\title{
PERSONA - AN OLD PUBLIC RELATIONS PROBLEM?
}

\author{
STEPHEN MACKEY
}

\begin{abstract}
This essay uses the neologism citizen public relations to express a view of the phenomena examined by persona studies implying that public relations studies might be regarded as an antecedent discipline to the former. It goes on to suggest potentially intriguing differences and similarities to do with political and epistemological problematics. The central theme is that the term identity is simultaneously the key link and the key contrast between the two disciplines. This is because the term identity is usually deployed at the internal, psychological, subjective level by scholars of persona while it is usually applied to external, material objects and events by the public relations industry and its academia. The essay also makes the point that both areas of study can be unified as different species of the genera rhetoric in the traditional sense of that still older field. This coincidence and dissonance may invoke a debate which can lead to theory development in all three fields. The fields are not comprehensively surveyed - a process which would be lengthy and might bring up many contrasting perspectives. Instead the work of representative leading authors is presented to make a prima facie case.
\end{abstract}

\section{KEY WORDS}

Public relations, persona, rhetoric, identity, image

\section{INTRODUCTION}

In "Making intellectual room for persona studies: A new consciousness and a shifted perspective" P. David Marshall and Kim Barbour write that: "Something quite extraordinary has shifted over the last twenty years that has led to this intensive focus on constructing strategic masks of identity". And: "...the construction of a public persona has become pandemic," (Marshall and Barbour). The below article takes the view that this something pandemic is the making available to many millions of people of the means of identity promotion swiftly followed by the motivation to use these facilities. Hitherto only corporations, governments, churches, political parties and other well-heeled interest groups had access to, and consequently could understand and exploit the full advantages of this exposition. The "strategic masks of identity" and "strategic form of communication" which Marshall and Barbour discuss in terms of individuals, were overwhelmingly the public relations work of these major organisations. Now, as in the advent of citizen journalism, digital media has extended these abilities to the many. There is what we might term a widespread citizen public relations. It is this which has become the phenomenon central to persona studies. In terms of rhetorical theory, scholars of public relations suggest: "A rhetorical rationale of public relations views it as a constructive dialogue, a 
wrangle in the marketplace of ideas, preferences, choices and influence," (Heath, Toth and Waymer). But this "wrangle" is at core the same sometimes deliberate but often serendipitous process which influences how people think about individuals. Similar rhetorical productions and consequences now apply as much to a teenager tweeting from a Melbourne tram as to a multinational car giant.

\section{DEFINITIONS AND EPISTEMOLOGY}

Pivotal to the below discussion will be the epistemological contrast of how both the terms identity and discourse are used in the Marshall and Barbour article compared to the preferred use of these terms in this critique. Discourse is a word which is usually unexplained in academic writing. For the purposes of this article it will be taken as Oxford English Dictionary definition 4a (Dictionary). 4a gives two distinct aspects to the notion. One is thought and the other is the material conveyance of that thought by speech, writing, or other concrete media activity. The term identity is also usually left to the intellectual predilection of the auditor. As will be argued below it is often loosely conceived as a mixture of external appearance, subjective-inflected perception, and inner conception. Much of the below will point out that in public relations, and it will be claimed in traditional rhetorical practice, identity is actually something quite different. It is something which is economically and in other ways concretely, objectively constructed.

The argument will be that for public relations identity is a concept which should not be allowed to collapse into ideational presumptions. The implication for persona studies of this public relations rubric is that an organisation's or a person's identity is not inflected by the enculturated imagination of the observer. Anything's or anyone's identity is always solid and real at any one time however it is observed. But every identity is observed in countless different enculturated subjective ways. These subjective observations involve images in the minds of the observers. Such an approach has the advantage of distinguishing between solid identity and plastic image. It overcomes the confusion which curtails making explicit the material provenance of both public relations and persona constructions and the motivations for these constructions. If how a corporation or person is, is more clearly separated from how they are thought of, more logical and thus potentially clearer political discussion is made possible. For instance consider the personas developing in and around the thousands of uncared for Syrian refugee children, some of whom are being trafficked in the sex trade in Europe after seeing their families butchered and blown to pieces. (Times_editorial), (Nelson). It is this history that should be seen as the concrete anchor to the identity of the personas under discussion. People's image of this situation or indeed young refugees' imagination of their own situation and thus their grasp on their own persona would be better rooted in reality. What is meant by this concrete material basis of identity can be further illustrated with reference to Erving Goffman:
If they know, or know of, the individual by virtue of experience prior to the interaction, they can rely on assumptions as to the persistence and generality of psychological traits as a means of predicting his present and future behaviour...Many crucial facts lie beyond the time and place of interaction or lie concealed within it. (Goffman 13)

In other words experience and facts are the real basis of identity, not psychology and presumptions, i.e. images and imagination. In a similar vein Kath Woodward writes:

Identity matters, but how and why it matters depends on time and place and on specific historical, social and material circumstances. (Woodward vii) 
Roland Robertson writes about the deeper epistemological implications of how the term identity is employed in sociology in his chapter "Aspects of identity and authority", (Robertson). Robertson discusses the Marxian, Freudian and the: "...Hegelianised Marxist talk of identity, or the 'identity principle'..." (219). Essentially Robertson discusses whether identities can be known objectively or whether we always view things subjectively. He makes the point that:

The various Hegelianised Marxisms lie between these two views, in the sense that they tend to focus on the concrete, historical circumstances of the degree of cleavage between the fusion of subjectivity and objectivity and between individual and society. (Robertson 220)

Robertson's discussion is a bit too highfalutin for the purpose of the present article. But it illustrates the level of complexity surrounding academic use of the word identity. This is a complexity which the present article claims to usefully simplify by explaining public relations studies in a way which might be loaned to persona studies.

To summarise: what follows are suggestions that: (1) persona in the sense of 'strategic masks of identity' and 'strategic communication' has a significant previous literature in public relations; (2) The epistemology of that literature is rather different from that of persona studies; (3) In consequence the older field of study might have something useful to say to the younger.

\section{IDENTIFYING IDENTITY}

The word identity is used 36 times in the Marshall and Barbour article. Before deconstructing the use there this article will summarise the way this term is generally used outside of public relations. The paradigm example of this usage will be taken as that explained in the 2013 book Identity: Sociological Perspectives by Reader in Sociology at Newcastle University (UK) Steph Lawler. This second edition is endorsed on the back cover by notable scholars in the field: Seidman, Skeggs, and Woodward. Seidman suggests: "Identity [:Sociological Perspectives] has established itself as perhaps the key reference point for students and scholars who want a smart and reliable guide through the thickets of identity discourse and analysis." In the book Lawler suggests: "It is not possible to provide a single, overarching definition of what it [identity] is ... because what identity means depends on how it is thought about," (7). Lawler is concerned with the indeterminate ways various cultures regard the very notion identity. She points to the fundamental difficulties for scholarship in this area because rational discussion about identities is dependent on some shared understanding of the term identity itself. But Lawler's complex concern contrasts strikingly with a concise definition by doyen of public relations studies James Grunig: "Image is what audiences perceive of an organization. Identity is what an organization chooses to use to shape those perceptions," (Grunig 127).

In the essay that follows, I will pursue the logic of Grunig's view and the views of other communication professionals, particularly those who write about corporate identity. We will suggest a treatment of identity which avoids Lawler's problems in favour of Grunig's approach. The below will also point to millennia of rhetorical thinking which supports the argument that the term identity should be seen as a strictly material, external-to-the-mind aspect of the semiotic process. The argument will be that these external consequences are outside the sight, auditory, tactile, olfactory, and taste boundary and that what happens inside the mind with respect to external material factors is not a process of identity.

Inside the mind a quite different process to do with images, imagery and imagination goes on. By inside-the-mind is meant processes of perception and conception. These are processes which involve an enculturated mental understanding - however useful or 
pathological - of empirical matters, of matters outside of the mind. These mental understandings, perceptions and conceptions are of course subject to discourses of culture and ideology in all sorts of ways. But they are perceptions and conceptions that are different from the things and thus the real identities of the things which are being perceived and conceived. The other point to bear in mind is that, as per O.E.D 4a the ideas in the discourses of culture and ideology which affect perceptions and conceptions are the flip side of material communication processes. What this means is that we must always realise that when external discursive forces and consequences are in Lawler's above words: "thought about" we enter a different domain an ideational domain. For these reasons we should conceive of thinking as a gateway. It is a transit point between the external material and the internal ideational. This thought-about domain is clearly a second stage phenomenon involving some mysterious spark of the person which cannot be comprehended by simply labelling it as semiotics. It is the domain of the production of complex and difficult to predict images.

Identity constructions and the discourses they deliberately or inadvertently convey are of course often architectonically the results of deliberate activity within ideational domains. But classifying identity constructions as a different category from images, imagery and imagination, seeing them as discrete external manifestations, has many advantages. This separation assists in efforts to attribute motive, origin, power relations and so on. It makes more concrete the possibility of investigating the manufacture and provenance of actual external entities which end up as significant factors in thinking processes. The separation enhances the possibilities of critical understanding of political and economic power relations; of the resources in time and money which have been expended; of the intricate workings of the technologies used; and so on. These are all material matters which offer themselves for objective analysis such that different ideological production and maintenance initiatives can be better understood. With this separation the finger prints of deliberate ideological work - all the material evidence of style; media budget; phraseology; communication channel; IP address; and so on might be gathered and forensically, as opposed to theoretically, analysed in a way which might identify instigators and their suspected motives, motives which might range from the therapeutic to the pathological. In the simple example of Lawler above her book-written narrative published by Polity is a material identification of her argument. That is, her own internal images are identified for the world to see via concrete literary production distributed by a publisher of many books of the political left. But our consequent images, what you or I imagine she means, our view of its plausibility, veracity and so on, is purely an internal matter for each of us; thoughts about what she means are the images which may vary considerably within different people. This variation may well be influenced by, but it is not determined by external identity-discursive processes. While we may have differing views of what she means, the words on the page, irrespective of how they are read, demonstrably have a single concrete identity.

In a similar way, for public relations and it will be argued for rhetorical processes in general, identity should be considered to be the external material part of any phenomena of communication while image should be seen as the consequent different internal intellectual abstractions which may occur in different people or which may not occur. Whatever internal intellectual abstractions arise will be images conjured up in an interplay with the ambient internal and external psychological and communication influences on that particular reader/viewer/listener, (or the detector of smell or taste if it is that sort of thing). The detail of each internal abstraction or thought will usually be hard to totally anticipate and will often have a complex relationship to its external material prompt. For example, just because the present author has presented a written narrative it does not necessarily mean the reader will think about it in the way the author intended. Regarded in this way images can be classified as internal and non-material phenomena which are quite different from identities. Images can be 
regarded as the hard to predict affect on the human facility of imagination which identity processes, if they are deliberate as in public relations and traditional rhetoric, deliberately try to effect. Prediction of the actual outcomes of the transit between identity and image and the ways image and imagination may then be harnessed, perhaps to create further identities, is very important to commerce and politics. Media agencies devote considerable empirical research and sometimes employ semiotic theory in an attempt to predict or monitor such outcomes. If persona is a term to do with how people and organisations are deliberately or serendipitously identified and about how they may, or may not consequently become images in minds, then the above discussion would appear relevant to persona studies.

\section{PERSONIFICATION OF ORGANISATIONS}

Marshall and Barbour understandably do not mention the personification of organisations. However the notion of organisational personality and thus the persona of a corporate entity is something which is necessary for the present article. The legitimacy of introducing this personification can be argue in the following manner: Corporations are referred to as legal persons in all the major jurisdictions of the globe, cf. as explained critically by Joshua Barkan in the chapter "Personhood" (Barkan). Furthermore, surely it can be allowed that all organisations are conglomerations of individuals? These may be individuals who are organised to conform to specific company behaviours, but clearly organisations are not inanimate. They are comprised of people. If personification is provisionally accepted the argument follows that, despite rarely using the term, public relations literature, and by implication corporate rhetorical processes generally implicitly deal with personas. And it is this corporate persona which is the subject of discussion when a public relations firm attempts to observe, research, create, and manage an organisation's identity. But the public relations literature about this activity demands that identity in this sense can only be about identity's material manifestation. The notion material in this sense does not just refer to signage and architecture. It also refers to that other side of discourse in O.E.D. discourse $4 \mathrm{a}$ - i.e. the material communication activity which is the counterpart to the thought. So, for instance thought - what one thinks about an organisation - will be part of the way its sales staff greet customers; the way its spokespeople present; the mission statement; its community responsibility declarations; its labour relations; its government relations; and so on. Both the declarations and their consequences - whether the promises of social and environmental responsibility are carried out or not for instance - are all tangible items. When they are recorded, but particularly if they are implemented, they comprise the concrete identity of the organisation at a stage momentarily before the organisation is perceived and images about it are created in the mind. In this way, as Grunig says above, identity can be considered the term for anything which an organisation does which may produce a way that it is thought about.

\section{PUBLIC RELATIONS IDENTITY LITERATURE}

In order to demonstrate the terminological definition in Grunig above, this essay now turns to the various uses of the term identity in public relations literature. For instance here is public relations scholar George Cheyney from his article "The corporate person (re)presents itself":

... identities refer to the specific identifying aspects of an organisation, such as names, logos, distinctive slogans and architecture and so on. Images are the broader impressions that are projected by organisations, the perceptions held by various publics. (Cheyney 174) 
Kendall sees an important aspect of identity construction in public relations as the effort to create an organisation's internal ideological and cultural climate. Identity construction is the work which affects how people in the organisation think and behave for instance towards customers:

\begin{abstract}
A related term, identity, describes efforts by corporations to establish how the public will perceive them ... corporate culture - which has been described as a company's shared values, beliefs and behaviour - in fact flows from and is the consequence of corporate identity. (Kendall 18)
\end{abstract}

Weaver, Motion and Roper express identity creation at the level of discourse production:

In this context public relations is understood as explicitly concerned with constructing knowledge, identities, and relationships that will work to facilitate particular sociocultural practices - those that will work for the needs and interests of the client organisation. (Weaver, Motion and Roper 18)

The above are examples of how the term identity is usually expressed in public relations. There are some examples of conflation of the term identity with image. But in general scholars and experienced practitioners shun the term image. Grunig who repeatedly refers to avoiding image in his own writing also says: "Bernays (1977) pointed out that 'image' suggests that public relations deals with shadows and illusions rather than reality," (Grunig) ${ }^{1}$.

\title{
CORPORATE IDENTITY CONSULTING
}

We can also look to a public relations speciality-corporate identity consulting-for considerations of image and identity. Early in his much cited, illustrated book Corporate Identity: Making business strategy visible through design, globally renowned consultant to many international brands Wallace Olins (1930-2014) wrote:
In order to be effective every organisation needs a clear sense of purpose that people within it understand. They also need a strong sense of belonging. Purpose and belonging are the two facets of identity ... A further component is how the organisation behaves: to its staff and to everybody with whom it comes into contact. (Olins 7)

These introductory comments by Olins illustrate his view, similar to Kendall's, that how an organisation is perceived by the people who are important to it depends largely on devising and implementing suitable internal ideological/cultural policies and procedures. Of course imagination and conjecture of a semiotic nature are involved at the ideational stage of this devising. But Olin's advice illustrates the way that the impressions which people eventually get about an organisation-the images which they hold about it inside their minds - can be affected by an organisational process which is totally external to the eventual viewer. This is a process which is largely material in that it requires a budget, staffing, staff training, and perhaps tendering to external specialists. Identity plans are then presented, explained and inculcated ideologically and culturally in ways which involve a great deal of meetings both for research and for perpetration. Perpetration involves a great deal of visual symbolism; what we might call ritual such as prize giving and social events; as well as other types of empirical communication activity. The creating and implementation of identity is not a process which is just imagined then simply injected into people's minds via cleverly chosen words and pictures. Olin's book advises how appropriate people-management structures should be set up to harvest the ideas of all relevant stakeholders so that a viable identity is devised. This should be a whole of organisation process to do with the actual identity of the organisation rather than a fantasy which the CEO 
and a few of her/his acolytes want instilled into people's minds. Olins's central message is that names, symbols, logos, awards to personnel, social and professional events, and so on should always represent something real about the organisation. They should be invested with clear and deep meaning for those who use, see, or take part in them. They should not be devised with the wistful hope that the eye will be attracted by startling or intriguing but meaningless colours and patterns; by insincere best worker awards; awkward congratulatory leaving do-s and so on. Visuals and rituals sometimes evoke notions about what are judged to be positive aspects of an organisation's past, for instance heraldic symbols, Latin mottos, statues, or pictures of founders. There may be allusions towards noble history in architecture such as we see in some $19^{\text {th }}$ and early $20^{\text {th }}$ century banks and public buildings. Olins congratulates Eric Hobsbawm and Terence Ranger for their book The Invention of Tradition. Hobsbawm, Ranger and colleagues describe the ways social cohesion, the legitimation of authority, and the inculcation of conventions, belief and value systems can be offered to the imagination of people by new symbolic and ritual productions which gestures towards the past (Hobsbawm and Ranger 9). They are writing at the level of nations and whole societies but Olins points out that the cultural and ideological work with they are depicting is in large part the same as the identity work which modern corporations engage in. The Invention of Tradition includes discussion of inter alia: Highlanders' clan tartans; Welsh bardic tradition revival; monarchical pomp and ceremony to cement Britons as loyal subjects of the Crown; representations aimed at legitimating British colonialism; the ways $20^{\text {th }}$ century European societies were normalised by the promotion of scientific and technological understandings. Olins's chapter on the invention of the identity of the Confederate Army could have almost slotted into the Hobsbawm and Ranger book. Among other symbolic inventions of the southern states the Confederates had to devise a new uniform to give the rebel army an identity. This had to be an identity which evoked loyalty and meaning as Americans but it had to look different from the Union's uniform. The result was a uniform which looked similar to that of the North but which was a lighter blue.

The last two sections have been about the way the public relations industry has of necessity had to clearly define identity as something different from image. The notion of identity has been discussed in regards to the affinity of managerial and corporate cultural processes, rather than image. We will now turn to the way theorists outside that industry-theorists who have no urgent requirement for that separation-approach relationships between the two terms.

\section{STEPH LAWLER'S IDENTITY}

As we have seen Lawler writes that: "...what identity means depends on how it is thought about" (7) This is of course is true. But equally what an Easter egg means depends on how it is thought about; what education means depends on how it is thought about; what global warming means depends on how it is thought about. From the perspective of the public relations and corporate identity industry and its academia there are two main problems with Lawler's approach. The first is Lawler's disregard of the base/superstructure problematic (Marx and Engels). Lawler's discussion is pitched at an ideational level which neglects concrete activity outside of the mind. Secondly she eschews the possibility of legitimate definition. One imagines that this difficulty has parallels to the Hegelian - Marxism problematic already mentioned in relation to Robertson. For instance Lawler writes:

Part of the slipperiness of the term identity derives from the difficulty of defining it adequately. It is not possible to provide a single, overarching definition of what it is, how it is developed and how it works (Lawler 7). 
The present essay thus far has provided arguments for a contrary view on all of the assertions and implications expressed in the above two sentences. Elsewhere Lawler writes:

As Regina Gagnier has wryly observed, "I may feel like a king but I won't be
treated like one at the bank". It becomes immediately clear that one problem with
the term identity is that it can be used to refer to a range of phenomena. My sense
of myself, others' perception of me, my reactions to others' perceptions, the social
categories that attach themselves to me and to which I attach myself - all may be
referred to as 'identity', yet clearly there are important differences between them.
(Lawler 7-8)

A critique of the above section from Lawler might go along the lines:

1) Regina Gagnier is clearly describing imagination - i.e. an image in her thoughts. This is an image separated from the reality of the material base of her actual identity - a person without lavish financial means. This is a playful delusion. But Lawler validates this delusion. Thus the notion of identity which is a concrete term in the field of public relations, is instead in Lawler's sociology turned into an image for use in ungrounded discourses. The possibility of the concrete notion that: "Identity is what an organization chooses to use to shape ... perceptions," (Grunig 127 ) is not examined.

2) Contrary to Lawler the four other problematics implicit in this extract, which incidentally are central to persona: a) sense of self; b) others' perceptions; c) reactions to others' perceptions; and d) social categories - might best not be referred to as identity. On the contrary a, b, c, and d are clearly images. They are the views which people hold in their minds. They are abstract notions. They are imaginings which can be contemplated in terms of semiosis. They are not concrete outcomes such as those deliberately and materially produced by for instance the market researchers, financiers, designers, and engineers of the new Ford Mustang car; by the history and hard artistic work of the Bolshoi Ballet; by the words being laid down as this page is typed. The latter three clearly result in a range of different images in different minds. However the material identity of the products of these three, certainly ideationally inspired, but in the last instance economic or administrative processes, can be seen to be at base actual and material. The identity of a car is shaped in metal, the identity of a ballet resides in its cast and choreography, a thesis, however speculative resides in some sort of visual or audible form, a form which corresponds with grammatical rules, years of study - study which has been material financially supported by the wages of the student or the taxpayer. All of these latter three phenomena have a materially produced and a concretely displayed identity irrespective of how they are inflected by the imaginations and other ideational factors which have been deliberately or unconsciously, innovatively or traditionally engaged with during those identities' design or consumption.

\section{DAVID MARSHALL'S AND KIM BARBOUR'S IDENTITY}

A major theme of this essay is that public relations studies does not subscribe to the conventional way that the term identity is employed in contemporary cultural and sociological academia while persona studies does so subscribe. What follows immediately is an attempt to justify this claim in respect of persona studies by examining a reading of Marshall's and Barbour's overview in the light of Steph Lawler's approach. It is hoped that the obvious enthusiasm for the public relation approach will not be judged too harshly. The section after this one will resume the previously introduced argument that public relations studies and persona studies are related species of rhetorical practice. 
In Marshall's and Barbour's overview there are 36 uses of identity and one only use of image which contrast considerably with how public relations studies might view the same subject matter. Their use of the word identity predominately indicates conceptual and perceptual matters which are happening in the mind rather than in the world. An interesting illustration of this is the use of the word mask. Mask is used as a strongly reifying metaphor. The term evokes a tangibility which seems to be about something real in the world. It conflates thoughts in minds with activities in the world. This non-separation reflects cultural studies' and sociology's conventional use of identity as depicted by Lawler who, as we have seen, admits the term's problematic nature. Examples of this indeterminacy include:

\section{Something quite extraordinary has shifted over the last twenty years that has led to this intensive focus on constructing strategic masks of identity. The catalyst is the development of online culture and its invocation to personalize the expression of a public self-essentially a persona-regularly and incessantly. (Marshall and Barbour 1)}

It is later explained that what is meant by "strategic masks of identity" in the present era are largely personas borne by digital technologies. But surely these are material constructions designed to project images in ways which have certain deliberate or serendipitous consequences in the minds of audiences? These may be targeted minds which have been professionally-commercially or amateur-socially pre-analysed for their imagination - their availability or vulnerability to certain flavours of image-implying messages. It is the vast sum of these complex internal mental generations - the varying images and views which are being perpetrated in people's minds - which considerably affects the "online culture" referred to. The real-world identity construction processes which deliver this imagery are the electronic innovations and the commercial, social, and sometimes egotistical exploitation of these concrete innovations. Such a clarification of identity construction as material happenings brought about by powerful forces outside the mind would have the effect of de-sensationalising, demystifying the "something", "pandemic".

Another conflation of image with identity which illustrates adhesion to the same dominant paradigm as that accepted by Lawler's is:

\section{Baddick summarizes this use of persona in literary criticism: "the assumed identity or fictional 'I' ... assumed by a writer in a literary work; thus the speaker in a literary poem, or the narrator in a fictional narrative." (Marshall and Barbour 3)}

In public relations studies terms this extract latently refers to identity work. But the identity work is the intellectual labour which includes literary scholarship and its expression via wordsmithing followed by the publication involved. These are the concrete identity constructing activities which are assumed but not emphasised in this extract. What is written about is the amalgam of affectual and intellectual insights which are borne by this behind the scenes identity work. The extract is about áffectual and intellectual insights designed with the purpose of harmonising with, or intriguing, or shocking, or otherwise modulating people's imagination. It is about the imaging and imaginative effects on a book-reading clientele or market. It is to do with the fictional image, or perhaps more accurately the image-fiction by which we as readers conceive the narrator or poet. It is not, as public relations might prefer, about the production of this imagery through the identity constructed by the scholarly, skill and industrial processes all of which had or have actual, concrete material existence.

The last example is undeniably about what goes on in the enculturated head rather than, as public relations studies might prefer, more concrete notions of identity and its construction. 
From reading Jung, persona represents something that needs to be overcome, or at least recognised for its threatening potential for leading to an unbalanced self where this externally driven identity can be mistaken for the whole being and there is "minimal" integration made with "one's own" inner selfor "individuality." (Marshall and Barbour 4)

Public relations studies would certainly agree that identity practices are external practices which result in the inflection or even the creation of the persona of an individual or organisation. But one needs to be clear what one means by persona here. Persona in this extract surely means a problematic involving a false or unhelpful conceptualisation of one's self or some sort of public social or propagandistic slander about who one is or how one thinks or behaves. But, as one would expect when contemplating an authority from psychology, these problematics are matters of the mind, matters of perception and conception. They may involve matters of abnormal psychology as well as matters of normal psychology. But they are not matters which public relations studies would entertain as identity matters or even matters of false-identity. They are matters of imagery and imagination. They are matters of how people think in terms of the effects of, or resistance to propaganda or information. In normal psychology they are the outcomes of the áffect and/or intellection passed on from cognitive contact with the unremarked-on actual real identity of concrete objects and concrete events in the real world.

\section{PERSONA - AN OLD TRADITIONAL RHETORIC PROBLEM}

In On truth and lies in a non-moral sense Friedrich Nietzsche writes:

What then is truth? A movable host of metaphors, metonymies, and anthropomorphisms: in short, a sum of human relations which have been poetically and rhetorically intensified, transferred, and embellished, and which, after long usage, seem to a people to be fixed, canonical, and binding. (Nietzsche in Ansell Pearson and Large 117)

Earlier in Description of ancient rhetoric Nietzsche had written: "The characteristic style is the proper domain of the art of the orator... he is an imitative artist; he speaks like an actor" (Nietzsche et al. 35).

It is beyond the scope of this article to detail a full argument of how persona studies might link to Nietzsche or his postmodern theory heritage. For the purposes of the present article however the increasing interest in Nietzsche's academic roots in the study of rhetoric and his remarks such as those above might be pointed out as relevant to the study of both public relations and persona. Both field are to do with using material communication means in order to project images and to respond to the images and the imagination processes in people's minds. Since the advent of print and then electronics this projection and responding has significantly involved those technologies. But the historic underlying processes of forming and influencing viewpoints, as Nietzsche points out, have always been that of the public speaker, the orator. So if oratory is taken in an updated wider sense to include modern means of speaking out and projecting character and reputation, then clearly both fields are touched by the above quotations. Persona studies in particular often refers to the actual mask of the classical actor which Facebook or Twitter users might metaphorically don as they represent themselves digitally. Similarly in common parlance there is no lack of critique that public relations activity is often an act which tries to put the best face on an organisation. The relationship between rhetoric and persona studies suggested here would need an article in itself. All that will be offered below is conjecture about what this link might mean if the above neologism citizen 
public relations is considered to have some merit. While confessing that invocation of the neologism makes only a tenuous link, the rest of this section will mostly be an attempt to firm up the relationship between public relations and rhetoric. There will however be some return to persona and rhetoric at the end.

Translating this discussion from the realm of public relations to the realm of rhetoric is not difficult. The terms rhetor and rhetoric occur throughout public relations textbook and research literature, for instance in the titles of books and chapters by: Cheyney and Dionisopoulos, Coombs, Elwood, Heath "Introduction", Heath "Wrangle in the Marketplace", and Ihlen. In a chapter about public relations' rhetorical role as the contested exchange necessary for democracy, scholar of rhetoric, public relations practitioner and leading theorist of public relations Robert Heath writes:

Rhetoric as a social force and process is a dialectic, the ultimate social process by which people learn how to enact society and through which narrative that enactment transpires. All of these criteria are basic to the full functioning of a community. (Heath "Rhetorical Enactment Rationale" 49)

Drug behaviour epidemiologist and critical scholar of public relations William N Elwood defines rhetoric as:

... the communicative means that citizens use to lend significance to themselves and to extend that significance to others. Rhetors or creators of rhetoric, include human and corporate citizens ... public relations is the strategic use of rhetoric to influence specific groups of citizens. (Elwood 7-8)

Aristotle's Rhetoric says: "rhetoric is the counterpart of dialectic" and that all people: "furnish explanations both to defend and to prosecute," (67 [1354a]). In other words when we try to convince someone of something we have to present our argument in a convincing manner which goes beyond simply giving the facts. We also have to be able to counter refutations. One only has to invoke discussions about global warming to understand what Aristotle was getting at in both of these statements. The scourge of climate denial has meant that initially environmentalists and now perhaps what we might call all right thinking people have had to constantly go beyond the simple climactic facts. Graphic descriptions of looming potential disasters have had to be made verbally explicit in attempts to create sufficient political support so that the bare facts are taken seriously. This process of argumentation conforms to Nietzsche's position that so called public truth emerges from "A movable host of metaphors, metonymies, and anthropomorphisms [...] which, after long [long enough] usage" become "canonical and binding" and settle the debate (117). But surely this is what happens throughout the presentational communication activities both in persona studies and in public relations? How a celebrity is projected into public consciousness is surely similar to how a brand is projected particularly when the former is hired as an endorsee of the latter, see for instance the web site Ranker (Ranker). It is not enough to say this project is good or this celebrity is glamourous. These facts may be correct. But both need to be clothed in the paint of textual and visual metaphor-rich description if that are to attract credence. A significant publicity campaign to this end would need to be a premeditated material activity by trained and experienced practitioners. Practitioners would shape and deliver this rhetorical discourse in a concrete process which has to be motivated and resourced. This concrete sometimes very expensive activity is the flip side of thought in the 4a O.E.D dictionary definition of discourse. In the same vein, the other quote from Nietzsche that the orator "speaks like an actor" evokes the notions of actor training, acting, voice projection, and all the other intellectual and presentational skills which are necessary in order for meaning to be imparted in a way that it gives effect to others' thought and action. The 
necessary training, apprenticeship, and practice to gain this skill is a material financial matter which costs money as the speaker invests in their future concrete professional identity. In the actual here and now performance the identity of the speaker is to do with the personal ethos which she is projecting which reflects on herself and her client. It is also exuded in the pathos which she generates in the communicative interchange with the audiences. These all involve material áffectual effect in the listeners and are at least as important as the logos - the factual part of the interaction. At this level of the characterisation of communication it is difficult to see much difference between what happens in the realm of standard public relations and the realm of citizen public relations.

\section{CONCLUSION}

Public relations, particularly when it is understood as the heir to traditional rhetoric, might offer a new slant on that other "strategic form of communication" which is overviewed by Marshall and Barbour. By requiring the term identity to refer to things concrete, the former field explains the latter field in a way which emphasises the manufacture of persona via material means. For the last 50 years at least the public relations approach has warned against confusing the term identity with the term image on the grounds of perspicacity and the argument that an understanding of and engagement with politics and economics is enhanced by this separate classification. The essay has also suggested that persona activities and public relations activities are different kinds of rhetorical activity. Both public relations and persona entities might be analysed and understood better if the identity of rhetorical effects and processes are thought of as concrete while their consequences in terms of how they affect minds are classified as ideational.

\section{END NOTES} relations.

1 The long lived Edward Bernays (1891-1995) is often referred to as the father of public

\section{WORKS CITED}

Ansell Pearson, Keith, and Duncan Large. Nietzsche Reader. 2006. Ebook.

Aristotle. The Art of Rhetoric. Trans. Lawson-Tancred, Hugh. Penguin Classics. London: Penguin Books, 1991. Print

Barkan, Joshua. "Personhood." Corporate Sovereignty. Ed. Barkan, Joshua. Law and Government under Capitalism: University of Minnesota Press, 2013. 65-86. Ebook.

Cheyney, G., and G. Dionisopoulos. "Public Relations? No, Relations with Publics: A RhetoricalOrganisational Approach to Contemporary Corporate Public Relations." Public Relations Theory. Eds. Botan, Carl and Vince Hazleton. Hillsdale, New Jersey: Lawrence Erlbaum, 1989. 135-58. Print

Cheyney, George. "The Corporate Person (Re)Presents Itself." Rhetorical and Critical Approaches to Public Relations. Eds. Toth, Elizabeth and Robert Heath. Hillsdale, New Jersey: Lawrence Erlbaum Associates, 1992. 165-83. Print

Coombs, T. "Crisis, Crisis Communication, Reputation, and Rhetoric." Rhetorical and Critical Approaches to Public Relations. Eds. Heath, Robert L., Elizabeth L. Toth and Damion Waymer. New York: Routledge, 2009. 237-52. Print

Dictionary, Oxford English. "Discourse, N.". Oxford University Press. Web. 
Elwood, William N. Public Relations Inquiry as Rhetorical Criticism : Case Studies of Corporate Discourse and Social Influence. Praeger Series in Political Communication,. Westport, Conn.: Praeger, 1995. Print.

Goffman, Erving. The Presentation of Self in Everyday Life. Harmondsworth: Penguin, 1990. Print.

Grunig, James E. "Image and Substance: From Symbolic to Behavioral Relationships." Public Relations Review 192 (1993): 121-39. Web.

Heath, R. "Introduction." Rhetorical and Critical Approaches to Public Relations. Eds. Heath, Robert, Elizabeth Toth and Damion Waymer. New York: Routledge, 2009. 1-12. Print.

---. "Rhetorical Enactment Rationale." Handbook of Public Relations. Eds. Heath, R. and G. Vasquez. London: Sage, 2000. 31-50. Print.

---. "Wrangle in the Marketplace." Rhetorical and Critical Approaches to Public Relations. Eds. Toth, E. and R Heath. Hillsdale, N.J.: Lawrence Erlbaum Associates, 1992. 17-36. Print.

Heath, Robert L., Elizabeth L. Toth, and Damion Waymer. Rhetorical and Critical Approaches to Public Relations Ii. Communication Series. New York: Routledge, 2009. Print.

Hobsbawm, E, and T Ranger. The Invention of Tradition. Cambridge ; New York: Cambridge University Press, 1992. Print.

Ihlen, O. "Rhetorical Theory of Public Relations." The Blackwell International Encyclopedia of Communication. Ed. Donsbach, W. Oxford: Blackwell, 2008. 4395-97. Print.

Kendall, Robert. Public Relations Campaign Strategies : Planning for Implementation. 2nd ed. New York: HarperColins College Publishers, 1996. Print.

Lawler, Steph. Identity : Sociological Perspectives. 2nd ed. Cambridge, UK ; Malden, MA: Polity Press, 2013. Print.

Marshall, P. David, and Kim Barbour. "Making Intellectual Room for Persona Studies: A New Consciousnes and a Shifted Perspective." Persona Studies 1.1 (2015). 29 January 2016 Web.

Marx, K., and F. Engels. The German Ideology. London: Lawrence and Wishart, 1970. Print.

Nelson, Fraser. "Sweden Shows How Not to Handle Migration." Opinion. The Age, Melbourne 2 February 2016, sec. Opinion: 27-27. Web.

Nietzsche, Friedrich Wilhelm, et al. Friedrich Nietzsche on Rhetoric and Language. New York: Oxford University Press, 1989. Print.

Olins, Wally. Corporate Identity : Making Business Strategy Visible through Design. London: Thames and Hudson, 1989. Print.

Ranker. "The Most Successful Celebrity Endorsements". 2016.

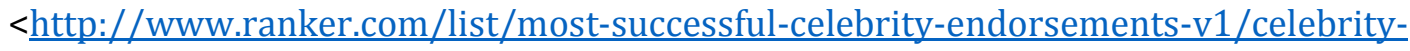
$\underline{\text { lists }>\text {. Web. }}$

Robertson, Roland. "Aspects of Identity and Authority." Identity and Authority: Explorations in the Theory of Society. Eds. Robertson, Roland and Burkart Holzner. Oxford: Basil Blackwell, 1980. 218-65. Print.

Seidman, Steven. Contested Knowledge : Social Theory Today. 5th ed. Hoboken, N.J.: WileyBlackwell, 2013. Print.

Skeggs, Beverley. Class, Self, Culture. Transformations. London: Routledge, 2004. Print.

Times_editorial. "Lost Generation - We Should Help Syrian War Orphans." Editorial The Times 26 January 2016, sec. Editorial: 21-21. Web.

Weaver, Kay, Judy Motion, and Juliet Roper. "From Propaganda to Discourse (and Back Again): Truth, Power, the Public Interest, and Public Relations." Public Relations Critical Dabates and Contemporary Practice. Eds. L'Etang, Jacquie and Magda Pieczka. Mahwah, New Jersey: Lawrence Erlbaum, 2006. 7-21. Print.

Woodward, Kath. Understanding Identity. London: Arnold, 2002. Print. 